\title{
Is Romantic Love a Linking Emotion?
}

\author{
by Swen Seebach and Francesc Núñez-Mosteo \\ Open University of Catalonia; Open University of Catalonia
}

\author{
Sociological Research Online, 21 (1), 14 \\ $<$ http://www.socresonline.org.uk/21/1/14.html> \\ DOI: $10.5153 /$ sro.3828
}

Received: 1 Apr 2014 | Accepted: 19 Oct 2015 | Published: 28 Feb 2016

\begin{abstract}
This article aims to provide a contribution to the debate about concepts that describe the empirically rich phenomenon 'romantic love'. The great variety of different facets of romantic love that exist and that we encountered in over 100 qualitative interviews and 4 focus group discussions carried out in Spain (Barcelona) and Germany (Leipzig) have inspired us to rethink existing definitions of romantic love. Rather than emotion or bond, the concept 'linking emotion' might help to capture usually rather unconsidered dimensions of romantic love. In order to discuss the value of defining love as linking emotion, this article will point at the 4 most important dimensions of love that we encountered in the analysis of our interviews. Results of our analysis will be compared with existing definitions of love, the usefulness of different concepts in order to define love will be questioned. Our empirically driven bottom-up approach will allow to discuss the usefulness of defining love as linking emotion.
\end{abstract}

Keywords: Love, Linking Emotion, Romantic Love, Simmel, Emotion

\section{Embedding}

Today, most of our cultural objects, all kinds of media products, advertisements, literature, self-help literature, films, artworks and songs but also photographs and self-made stories play with, refer to, or base on the topic of romantic love. Romantic love is a, if not the center of late modern culture. From our point of view, this centrality of romantic love in objective culture (Simmel 1997: 45ff; Cantó Milà, 2013) reflects the importance of romantic love in our lives. Romantic love has become a centerpiece of current social bond making and is central to how we become and feel part of our modern society (Campbell 1987; Seebach 2015).

Within the huge cultural industry (as the organized and capitalized production of objective culture), woven around the topic of love, we can find various versions and meanings of love. We can find imageries of romantic love, seductive love, platonic love, everyday romantic love (life), erotic love, making love, sad love, and narcissistic love. Even if we just focus on romantic love we encounter a myriad of different facets that do not easily fit into each other. In our daily consumption of cultural imageries, congealed in cultural objects, we are confronted with the ups and downs of partner search, with the enchanting moments of falling in love, with the advantages and disadvantages of having a stable partnership or having an affair, and with the cruelty and intensity of a separation from a partner. By releasing always-new love related products, today's cultural industry produces romantic love in always-new ways, reiterates love's "essence" in always-new forms. However, this rich diversity of love is not only to be found in the sphere of objective culture but also within the millions of different lives and love stories of couples.

1.3 Consequently, we could say that despite its centrality to modern society, love is made of a variety of parallel existing narrations of love within the cultural and the experiential sphere, that emphasize different facets of love, which go beyond each coherent definition of love (Scheff 2010).

1.4 In social science, we usually treat the phenomenon "love" and subsequently the phenomenon of "romantic love" as if we would share all one and the same definition of it or as if the central question is whether love is an emotion or whether it is a social bond. In fact, literature discussing romantic love has focused centrally 
We believe that the focus of this debate has complicated a profound discussion of the multifacetedness of love. Love might be an emotion but if so, love is doubtlessly a very special emotion, with very own attributes. We believe that pointing at the limits of existing definitions of romantic love is crucial for refining future analyses of love. To test whether different concepts fit with the richness of love as social phenomenon might not only help to define romantic love/love better but to open up and understand a little better the social reality that we want to describe when we use the term romantic love/love. Therefore, this article will focus on romantic love as a possible linking emotion.

We understand as a linking emotion, an emotion that not only has a social dimension but that creates a link between those who feel it and those for or because of whom they feel it. The creation of a link can be understood in two forms, on the one hand as the simple simultaneous birth of emotion and bond, on the other as the production of the conditions that love as emotion and social bond can become possible. We believe that for romantic love both are the case.

\section{Framing Love}

2.1 Based on our findings we take romantic love as something that we do not only feel but that relates people with each other, and analytically separate it from e.g. unrequited love, or other forms of one-sided love. In fact, this differentiation allows us to separate between desiring someone and romantically loving someone. Romantically loving someone means to find fulfillment in the reciprocity of a durable link or social bond, whilst desiring someone can be a purely solely act (compare with Simmel's two accounts of love in Simmel 1950: 379 vs. Simmel 1984: $154 \mathrm{ff}$.). We found affirmation for this analytical separation in over 100 qualitative interviews in which our interviewees never talked spontaneously about unrequited love when we asked them to talk about love, to define love and to tell us their love story/stories.

2.2 We decided to focus our work and also the discussion of this article only on romantic love. We are aware that other forms of love are also meaningful in today's society, relevant to the construction of meaningful social bonds. Two important other love forms are filial love and friendship. However, from our point of view, romantic love is special because, on the one hand in contrast to the relationship between mother or father and child, romantic love unites two (or more) individuals who have a certain freedom when choosing each other. On the other hand in contrast to friendship, the romantically involved individuals, do not only share a bond, based on mental but also of physical intimacy, with each other. The erotic encounter between the romantically involved individuals demands a much stronger interpenetration between autonomous systems/entities (compare with Luhmann 1986: 28).

\section{Methodology and Fieldwork}

3.1 This article presents reflections on the empirical findings from over 100 semi-structured in-depth interviews and 4 focus group discussions that were carried out in Barcelona and Leipzig between 2010 and 2013 in a research project funded by the Spanish Ministry of Science and Innovation[2].

3.2 We decided to do interviews and focus group discussions in Germany and Spain in order to be able to compare whether there are possible national or regional differences between 'love-stories' in Germany and in Spain. Furthermore, by doing research in two European countries we wanted to make sure that we could make some general assumptions about romantic love relationships, at least for a European context.

3.3 An important challenge that we faced carrying out our research was the translation of different love terminologies. E.g. to love in German (zu lieben) means nearly non-ambiguously to romantically love whilst the Catalan estimar-se or the Spanish querer are much more ambivalent. We dealt with this difficulty by extracting the particular meaning of love according to the concrete contexts in which it was used and according to the performance of the interviewed whilst using it.

3.4 We gathered our data according to the principles of the Grounded Theory (Glaser 1992; Strauss \& Corbin 1997). The Grounded Theory allowed gathering and analysing data in a very open, empirically inspired way and it allowed us to revise not only our findings but also our methods and definitions during the course of our research. Working with interviews and focus groups with Grounded Theory principles we were able to create a vivid, concrete and reciprocal interaction between the interviewed, the data and the theoretical concepts. We were able to clarify certain points together with the interviewees and we were able to provoke in some cases an 
engaged, critical reflection on the variety of facets of romantic love that coexisted in our interviewee's narrations of love, in the experiences they told us about.

\section{Findings}

4.1 In order to capture the full meaning of love in people's lives and consequently to discuss whether the concept linking emotions is useful to define romantic love, we compared the aspects of love that interviewees and focus group participants provided us with when we explicitly asked them for a definition of love with when they implicitly talked about romantic love within their narrations. Furthermore we compared the aspect of romantic love that people focused upon when they talked about romantic love in a more abstract way with aspects they focused upon when they talked about love in relation with very concrete experiences. We also looked at the differences of using love in narrations about moments of romantic enchantment and in those narrations about everyday life, and their most unromantic moments. Only after having collected this great variety of different empirical uses of love, we started to cluster them and matched them then with different existing definitions of love and with the concept "linking emotions".

4.2 Using this careful bottom-up, empirically driven approach we were able to see what romantic love meant to our informants and which definition would be the most fitting to describe what people experience as love. Furthermore, our method allowed us searching for possible gaps between different existing concepts for defining love and our empirical findings.

4.3 A first result that we gained through our analysis was that gender had no significant influence on how people use the term love. Both, men and women used the 4 facets of love that we are going to discuss in this article. In fact, rather than our informants' gender, whether their last love relationship had failed and how it had failed was relevant to their perception of and perspective on love.

4.4 This does not mean that there were not some differences between men's and women's love narrations. In fact, the contents of narrations told by men, and the contents of narrations told by women showed some clear gender differences. E.g. the reasons why men defined a moment as a special, and magic differed from why women did so. There were also some differences with regard to the perspective from which men or women talked about and narrated their love relationship and their special moments (I-centered form vs. him/her-centered form). However, we will not discuss them in this article, as both, men and women, used the four dimensions of love within the interviews/focus group.

\section{The Impossibility to Define Romantic Love}

4.5 A second important finding that we extracted from our interviews and focus group discussions was that none of our informants felt the spontaneous need to explain what love was for her/him. They were all quite sure that we all implicitly shared one and the same definition. This became especially clear in the focus group discussions in which participants started talking about love with us and with the other peers without checking whether we were all talking about the same phenomenon. It became furthermore reflected in their surprise when they realized that sometimes their use of love would not fit with the uses of others.

4.6 Another good indicator for the presupposed shared meaning of love we saw when we asked our informants to define love. They were generally surprised by the need for such a question 'because everybody knows what romantic love is' (participant of a focus group, Barcelona).

4.7 However, asked for a definition nearly all of our informants struggled with providing a simple answer. Most of them stopped talking, and started thinking about how to define love best. It was only after thoughtful moments that they either outlined romantic love by providing a concrete (sometimes very personal biographical) example:

'Romantic love is this... you know when you see the other...you know... like... when I saw René and I felt that's it. He is the one.' (Elizabeth, 29, Berlin)

4.8 Or by relating it to a common image with which we socially usually identify 'love':

'Romantic love is you know, you can't control it. Suddenly it is simply there, you know.' Juan, 19, focus group, Barcelona

'Romantic love is this feeling that you experience when you see in the others eyes and you get this strong sensation of ...wow. Two gazes that meet, find and fall for each other that's it. (blushes)' Ana, 18, focus group, Barcelona 
In some cases romantic love was defined with a direct reference to objective culture, to one of those love stories that we use as cultural referents. This was especially the case in the focus group discussions in which young peers tried to harmonize their use of the term romantic love with the uses or possible expectations of others, on the one hand however trying not to give too many personal intimate details.

'Romantic love is something that comes to you... like in these movies... like in ... well I don't know. When you meet
and you fall in romantic love and you can't help it.' Berta, 18, Focus Group, Barcelona

'Romantic love is like in this Greek story of Aristophanes. It is about finding your other half.' Elise, 22, Leipzig

4.10 The different forms to answer our explicit request for a definition of romantic love invite us to some interesting thoughts and reflections. First, they show clearly a coexistence of different understandings of romantic love on an experiential level (of subjective culture) and on a cultural level (of objective culture) in the images, imageries and culturally shaped symbols that we share with each other.

4.11 Second, both, the meaning of love on an experiential and a cultural level are somehow connected with each other. Consequently, our informants shifted smoothly between the two of them, although they were not equivalent.

4.12 Third, the use of different discourses on romantic love, and subsequently the use of different foci on the phenomenon love, depends on different factors such as individual biographical experiences, the context in which romantic love is used, and the social embedding in which the interview or focus group discussion is made.

4.13 In our interviews and focus group discussions, those in a romantic love relationship rather opted for defining romantic love via a concrete personal experience whilst those who were not defined romantic love rather through a culturally fixed image. Those talking with the interviewer in a more or less private or intimate environment were more likely to opt for defining romantic love through an experience whilst those who were asked for such a definition in a public space (focus group participants) preferred defining romantic love through an object of objective culture.

4.14 Fourth, the specific focus through which people look at romantic love has consequences for how people narrate their love story. Different aspects of the love phenomenon evoke different discourses and transform the way we narrate what we felt and experienced.

4.15 Those, opting for defining romantic love via a specific life moment, sketched instantly romantic love as a part of their subjective universe of experiences. Romantic love was then imaginatively extended from one specific moment to the whole romantic love history. Informants communicated about romantic love as something that they had felt and experienced, as something deeply attached to a specific moment, as part of a shared world of experiences with the partner. Within their narrations, romantic love appeared rather as a description of different photographs narrated in first person.

4.16 Those, defining romantic love via a fixed cultural image, started to think love from the perspective of manifest objective culture, and so from a common place that allowed them to emphasize romantic love as a common denominator, as a social metaphor. Defining romantic love that way, allowed them to capture and define love, by substituting it, in the same way that an image or a sign can substitute a material object, or an experience. However, people from this group (those not in a romantic love relationship and those in the focus groups) needed time to explain how this general and universal referent was able to durably relate them with a partner, how the cultural images, imageries and symbols of romantic love were connected with their experiences of romantic love within their past, present and future romantic love relationships.

4.17 In our analysis of the interviews and the material from our focus group discussions, we compared the immediate answers to our question 'What is love?' with all other moments in which love was in some way used. As a result we were able to crystallize four different sides, or aspects of romantic love that despite sometimes profoundly opposing each other, turned up in one and the same narration.

1. Romantic love as a feeling, as something that people experience as a part of their subjective culture.

2. Romantic love as a (n emotional) social practice, as that what relates people with their partners.

3. Romantic love as ideal reflected in the idealization of one's own romantic love story and in the ideal, however not idealised romantic love in objective culture. 
4. Romantic love as a social institution/social bond, spending and providing the romantic love bond with a certain durability.

4.18 These four different aspects of romantic love were not found in a pure form but appeared often in a variety of different mixed forms within the interviews and discussions. The use of different combinations of defining romantic love largely depended on the embedding in the love story (when in the narration it was being used), and the concrete contexts in which love was used. However, we believe that all four uses or dimensions of romantic love emphasize fundamentally different, however equally important aspects of love.

\section{Romantic love as practice and romantic love as feeling}

4.19 In the narrations on their romantic love stories, our informants usually brought together two different dimensions of romantic love that they united in the very same narration, sometimes in the very same phrases. They described romantic love as a feeling that they had felt in this or that moment, and they described romantic love as a part of the practice, or performance with the partner - a kiss, a gaze, a talk.

4.20 This was especially the case when they narrated about the special moments that they had spent together with their partner. A narration concerning one of these special moments was commonly provoked when we directly asked for the important moments within our informants' romantic love stories. But also when our informants narrated freely about their romantic love stories or when they tried to define romantic love they talked about such special moments (especially those participating in individual interviews).

\footnotetext{
'I sat there and then I saw René and he saw me and it was just like...I felt that's it. He is the one. It was in the way he looked at me... It made me feel so vulnerable.' Elizabeth, 29, Berlin

'I remember once I had had such a bad day, and was really in a terrible mood. Stress at the university, homesickness... you name it. And he said "Let's go for a walk in the woods....' 'Have you seen the sky? It's going to rain.' I replied. No, it won't. He said. So self-confident that I believed him. And so then we were climbing up the hill under the darkest sky you could imagine... And it started to rain... so heavily... it was really raining cats and dogs. But the thing was... I didn't care anymore! We climbed up the hill holding hands under the pouring rain ... and yes... if you tell it this way... it may sound stupid. But it didn't feel stupid at all. It was one of the most wonderful moments in my life. My bad mood was gone. We stood on top of the hill looking at the city wearing its spring colours under the rain... and... and... it was like discovering why I was alive, and that my life was forever tied to his... to him.' Greta, 39, Barcelona
}

4.21 On the one hand, romantic love appeared as a part of the actions or interactions with each other: Romantic love is in the gazes that lover's exchange. Romantic love is also in a walk through the rain. Romantic love is in a phone call that someone might make to talk with a partner or in the kiss of two people in love that meet again after having been separated from each other.

4.22 On the other hand, romantic love was described as fundamental part of an inner experience - a feeling. Romantic love as feeling can make you 'feel more than alive'. It can also make you suddenly realize that someone is the special other(s).

4.23 That perception, experience and practice are interrelated with each other making it difficult to distinguish were one finishes and the other begins and that feelings/emotions play a crucial role in linking perception, experience and practice, should not come as a surprise. In fact, Hochschild (Hochschild 1987: 28/29; Hochschild in Greco/Stenner, 2008: 121ff.) and Illouz (2009: 382ff.), both discuss the interrelatedness between perception, experience and practice/performance via emotions within their works. For both authors, emotions/feelings are central to the synthesis between social actions/interactions and individual experience. In fact, emotions/feelings run through both, social and individual, dimensions, from a perceptive via an experiential to a performative phase, uniting each with the others (Illouz 2009: 383).

4.24 When we compare our findings from the interviews with the thoughts and reflections of Hochschild and Illouz, it is obvious that they fit well into each other. We can see clearly that in this sense romantic love has a lot in common with other emotions. Romantic love runs also from a perceptive, via an experiential to a performative phase. In this sense we can understand romantic love as a typical emotion.

4.25 However, we also discovered something in the interviews that makes romantic love different from other emotions. In the interviews, our informants explained repeatedly that a central reasons why they had such a 
strong experience of love in a specific moment was due to knowing that the other had the same experience, that she/he was also feeling love, and that they 'consequently shared this moment of love with each other'. In fact, the feeling of the other and the synchronicity of experiencing love was the very condition for being able to experience love at all.

4.26 If we use Hochschild's terminology, we could say that in the case of romantic love the feeling rules, the socially imposed possibilities and limits for an emotional experience, come from the concrete interaction with the beloved other, from the emotional link of love relating one individual with its beloved other. The other's successful performance of romantic love itself is the very condition for the experience and performance of love (Luhmann 1986: 28) and vice versa. Romantic love demands reciprocity and symmetry. Reciprocity and symmetry does not mean equality. In fact, as we know from anthropological studies of reciprocity (Mauss 2002) reciprocal partners are never equal, there is always an inequality of power. It simply means that there needs to be a certain form of interrelationship (Wechselwirkung) between those in love.

4.27 Experiencing romantic love as a feeling, enacting romantic love as an emotion and being enforced in the experience of romantic love through the perception of the reciprocity of romantic love, romantic love creates a circle in which the two individuals move from an individual to a social level and backwards engaging always closer and tighter (Collins 2004: 48ff.; Seebach 2015). If we take into account the deeply social, reciprocal, and cyclical character of love, we have to acknowledge that romantic love is different from other emotions: autopoetic, based on the link between and the linking of all involved subjects.

4.28 Romantic love is in and in-between those people in love, inner experience and outer social practice at the same time. It is a part of and at the same time beyond the individuals in love, 'beyond this I and Thou' (Simmel 1984: $154 \mathrm{ff}$.) in which we would usually group human actions and interactions. For Simmel, where romantic love exists 'the I has felt its way across the hiatus to the Thou. The existential will of the I flows to the Thou with complete intimacy. It does not need a bridge, which separates just as it connects.' (Simmel 1984: 155).

4.29 This very special character of romantic love turns it into something special that bridges the gap between individual feelings, social emotion and social tie.

\section{Romantic love as an ideal and romantic love as a not ideal object of objective culture}

4.30 Another aspect of romantic love we discovered in contexts in which different informants talked about their romantic love ideals. Love as ideal was especially brought up when we asked people for how they imagined a perfect romantic love story and when we asked them for their ideal of love. We expected them to talk about a film they had seen or a book they had read. Short, we thought that they would talk about different cultural objects that reflect the purest and most perfect forms of romantic love. We imagined that with our questions we would provoke our informants to relate, compare and contrast these 'polished' elements of objective culture with their personal romantic love relationships.

4.31 However, we were partly wrong. The answers to the question 'What does your ideal of romantic love or ideal romantic love relationship look like?' were not related with the mini-myths of objective culture, at least not directly. Especially those people in a stable partnership did not choose a romantic love story from a movie or a song in order to describe what their ideal of romantic love looked like. In general, movies or songs were seen as either too much stereotyped or at least as disconnected and somehow profane compared with an own romantic love story. Instead of using these common images, especially those people in a partnership expressively declared their own romantic love story to their ideal:

'What would be a perfect love relationship for you? Mmh... let me think... no there is no such thing, ...not like in a movie or something... Our own story.' Nishka, 32, Berlin

'An ideal relationship? Well... our relationship...' Irene, 22, Barcelona

4.32 The reason why people defended their own love story as ideal compared with the ideal romantic love stories provided by objective culture is noteworthy. It might be that romantic love image(rie)s produced by the cultural industries in objective culture generalize romantic love too much. In fact, the commonness and universality of the love image contradicts with what we desire from love: something special, and unique. Its universality is what makes it a reference point for many but hinders us from seeing in it an ideal. 
4.33 What we mean is that a love story from a book or film deeply contradicts not only any idea of a personal very intimate romantic love story but the 'post-religious' (Beck and Beck-Gernsheim, 1995) fundaments of romantic love itself. A romantic story told in one of the narrations of objective culture is neither their, nor someone's magical romantic love story but only a story that as metaphor helps people to understand and share the meaning of romantic love socially with each other. It might trigger imaginaries of love and the imagination of an own love story (Campbell 1987: 92). However, it has lost contact with what we could call the sacred grounds of love. As for those in love such a generalized image can only appear profane.

4.34 It should also not come as a surprise that for those in a love relationship their own relationships is ideal. According to Sternberg, an important part of a successful love relationship is related with turning one's relationship into a special story (Sternberg 1999): one's own sacred intimate love story, one's own myth of love. In such a story the couple interweaves elements from objective and subjective culture via shared experiences, unites romantic love as an emotion with romantic love as an alignment of special events, magic moments and quotidian life.

4.35 It is these very own love stories that inspire couples, bestow their love lives with meaning and a higher purpose, and enrich the profanity of their day-to day existences with their partner. In this sense, these romantic love stories are a unique non-generalisable form of a love myth, ideal places in which couples find meaning for their love relationships. They create places that are non-exchangeable, unique and holy, intimately shared with, communicated about, and remembered within the couple (Seebach 2013).

4.36 Those who are not in a stable partnership do also not relate their ideal of romantic love directly with an image or symbol of objective culture. Instead they rather develop on an imaginary in which they negotiate possible ideals, with images and symbols from objective culture and with realistic probabilities for a romantic love story to become true (compare with Campbell 1987: $215 \mathrm{ff}$.). This negotiation process between fragments and images of cultural love stories and own memories, desires and dreams for the future was sometimes explicitly expressed:

'You grow older, and you gain experience, and you're not that romantic teenager anymore who looks for the prince that will lead her to the enchanted castle. You start valuing more quotidian things, and become sceptical of big promises.' Elisabet, 38, Barcelona

4.37 It is in this sense that two ideals of romantic love coexist - romantic love as an imaginary negotiated between idealistic thinking, realistic possibilities and cultural signifiers and romantic love as an ideal story, made of concrete experiences, quotidian time and special moments with a partner.

4.38 In people's memories the meeting of two ideals can coincide. From our interviews and from the literature we know that e.g. watching movies or TV series together is an important part of sharing experiences and spending time together. In fact the joined consumption of and communication about love stories in objective culture are a very essential part of many couples' (ideal) romantic love story (compare with Illouz 1997).

\section{Romantic love as a social institution/social bond, spending and providing a certain durability}

4.39 People defined romantic love as an emotion, as an ideal and as a relational action or performance.

Furthermore they defined love also as something that is durable in time, that provides those in love with a certain security and gives them the ability to imagine a tomorrow together with their partner, an intimate social tomorrow. Romantic love creates not only the belief into this tomorrow but it invokes actions that make this tomorrow possible. Based on the past, love bestows present and future actions, and interactions with a direction and with meaning. In this sense romantic love must be understood as an institution (Berger and Luckmann 1967: 72). Once in a partnership built on romantic love, romantic love demands a systematic performance of love rituals (Illouz 1997) and fosters the creation of a set of specific norms that bind the lovers with each other.

4.40 Moments, in which romantic love appears in its function as institution, are rare and in the narrations of people almost invisible. In fact, nearly no informant explicitly talked about love as an institution. However, this does neither mean that the role of love as creator of shared norms and a context for reciprocal interactions is not meaningful or important.

4.41 A main reason for this invisibility of romantic love as an institution in people's narrations is that in a wellfunctioning love relationship the institutional character of romantic love is completely immerged in people's dayto-day practices. In fact, couples usually take the durability and meaning spending character of romantic love 
simply for granted. Even the ritualization of love life is almost invisible as the contents of love rituals change constantly.

4.42 The only moments in which people explicitly discover love's role as institution are: First in relation with explicitly socially defined forms of romantic love such as marriage. Second, their reflections about the future of their love relationships in which they take their love and their relationship built on love for granted show an institutional dimension of romantic love. In fact, most of our informants simply took the tomorrow with the partner for granted, expected the relationship to continue as it was, and hoped to built on the basic fundaments, routines and rituals that they had constructed with their partners.

4.43 Third, romantic love as an institution becomes a topic when there is serious trouble in a love relationship. In fact, our informants talked about love when they had with their partner or had had problems with a former partner. The explicitness of love as an institution in people's narrations of love meant that their trust and confidence in love as an institution had been profoundly shaken.

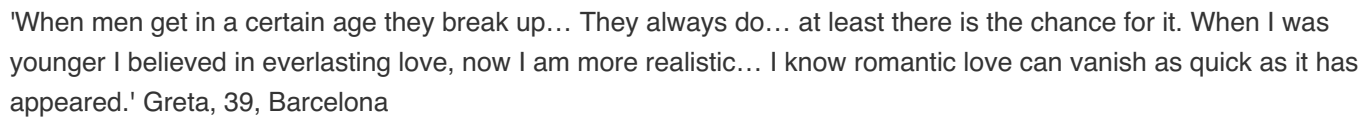

4.44 If we try to analyse why it is mainly those in relationship trouble who are aware of the importance of love as an institution we find three possible answers.

4.45 For the first answer, Hochschild's The Managed Heart (1987) provides helpful thoughts. According to Hochschild, in those moments in which feeling rules, feelings and emotion performances fit with each other there is no need to become reflexive of feeling rules, own feelings and consequent emotion performances. As a consequence, the individual does not gain a reflexive distance to his or her own actions, perceptions and experiences at all.

4.46 However, a mismatch between existing feeling rules, feeling experience and emotion performance creates the need to actively regulate one's emotions/feelings, to intervene reflexively into experience and performance. In fact, it is only such moments in which an individual gains the necessary distance to become aware of feelings and the need to adapt or manage them. Only such reflexive moments lead to the creation of a memory of emotion and the existence of feeling rules (Hochschild, 1987: 43).

4.47 Even if what Hochschild describes is not meant for the analysis of the mismatch between institutions and emotions, her thoughts might help to analyse the creation or non-creation of a memory of romantic love as institution. Taking Hochschild's viewpoint, we become aware that one reasons why someone might start to think about the importance of romantic love as a durability spending emotion/institution is that he or she has the impression that this emotion/institution is in danger. This might happen when the institutional framework does not fit any longer with what a person feels and perceives. For example when we suddenly feel that our routines with our partner feel uncomfortable and meaningless we might feel the need to intervene in our emotional experience and our emotion performances of love. In such a moment we might become aware of the existence of love as an institution, and of its feeling rules.

4.48 The impression that we need to take a step backwards, away from our immediate experience of love, and to reflect on what we do, feel and what is demanded from us might be temporary. It might result from a specific event with our partner or it might foreshadow the relationship's end. However, even if only temporary the memory of the mismatch will stay. It will become something durable that might only be forgotten if there will be no further mismatches in the future.

4.49 A second reason for the non-explicitness of romantic love as an institution in our informants' narrations might be that in our society love has become something like a post-traditional religion (Beck and BeckGernsheim 1995). In such a religious-like context, the crucial question for the believer is whether she/he believes or whether she/he does not believe. Actively reflecting on love's durability spending character and on romantic love as an institution, would demand a critical distance to this, for the lovers, holy and therefore irrefragable phenomenon. Turning it into something doubtable would mean to desecrate it.

4.50 A third reason why only a few informants mentioned love as institution, might have to do with what the romantic love relationship represents in modern society. The romantic love relationship has to unite two 
independent individuals, creating a strong bond between them, however under the highest possible freedom (Luhmann 1986: 13). Romantic love defined as institution opposes such an independence emphasizing, reciprocally renewed romantic love. In fact, thinking romantic love as institution anti-authenticises love as a continuous free choice of two independent individuals, and deeply questions the immediateness of the bond of love.

4.51 Whichever might be the reason, all three might help to understand why love as institution was nearly never discussed explicitly. This does not mean that love as institution was not important to the people we interviewed. Most narrations of people's romantic love stories were stories of their love's institutionalization - of getting to know each other, developing trust, routines, and rituals, of establishing norms and limits and of constructing a tomorrow on these institutional fundaments in order to imagine an immediate and not so immediate future. In fact, implicitly romantic love as an institution was found in nearly all the interviews, often closely related with the discussion of the importance of trust.

4.52 As we already explained, especially in those cases that informants were in a relationship in which there was no trust or at least in a relationship in which there were doubts about trust, love as an institution became an important explicit topic.

\section{Is Romantic Love a Linking Emotion?}

5.1 If we look at the 4 dimensions of love that we discovered within our interviews and our focus group discussions we become aware of the limitedness of existing definitions of romantic love. Whilst most authors classify love either into the category emotion and/or relation there is only a few authors going a little further. There is e.g. Kemper's definition of romantic love $(1987,1989)$ as an emotion and as a social bond that is based on reciprocity and the balancing of power and status within this reciprocal relationship. However, neither the institutional durability spending part, nor the link between love as experienced and consumed ideal play a role in here (something that we rather find in Sternberg's work (1999) or in a completely different way in Beck and Beck-Gernsheim (1995). Aaron Ben- Ze'ev's definition of romantic love as one of the 'positive emotions directed at others' (Ben-Ze'ev 2001: 406) captures also a majority of our empirical finding, however also misses a part of the love phenomenon.

5.2 In fact, Ben-Ze'ev himself emphasizes that love is different from other positive emotions directed at others as it bestows the link or bond it creates with a much greater durability than other emotions directed at others (Ben-Ze'ev 2001:32). Love's specialness raises fundamental questions regarding the usefulness of defining love as positive emotion directed at others. Doubts fit with our empirical findings in which we discovered that love is not only an institution but an autopoetic, reciprocal institution, emotion and bond.

5.3 For us defining love as linking emotion is an effective answer to the quest for a definition of romantic love. Therefore, we focus our discussion now on the usefulness and limits of defining romantic love as a linking emotion. From our perspective, the concept linking emotion is different from other discussed concepts because a linking emotion does not suggest that the emotion is first and predominately an individual, or individually experienced phenomenon that is then projected towards an Other. Instead it is the emotion itself that is the link between the emotionally involved subjects. The linking emotion makes the emotional experiences possible. Feeling and linking are simultaneous. In this sense we could say, the feeling is the link.

5.4 When we match our empirical findings based on people's uses of romantic love with the concept 'linking emotion', we see clearly they fit well. Romantic love is emotion, but an emotion that not only generates but also needs to exist as a social bond, in order to be felt. Romantic love is created and experienced collectively. It links those who feel it together and it is fundamentally based on a certain reciprocity, and collectiveness. Like other linking emotions, romantic love unites an individual and a social dimension: two lovers and their interrelationship create something that is irreducible to the sum of the two individuals in love. Consequently we can affirm that defining love as linking emotion allows capturing a great part of our empirical findings.

5.5 However, love transcends such a definition. Romantic love has further facets that go beyond the characteristics of a linking emotion. Illouz $(1997,2012)$ has emphasized that love is emotion and sentiment, which brings another dimension to the love phenomenon. Also Simmel (1984) might serve as a reference point. In fact, especially Simmel's later texts might be approached best in order to define romantic love. 
both the romantically involved individuals and, on a social level, something that is beyond the two individuals and their interests, needs, demands and desires. Consequently, we discovered love as emotion, as a relation but also as an institution, and as the link between them captured in the idealized love story. Simmel is one of those authors who have been aware of this ambivalent and multidimensional phenomenon that love is. This becomes especially clear in On Love - A Fragment(1984). In this work, Simmel expressed the special character of love by defining it as something that is a part of the two individuals in love but also between them and furthermore 'beyond the I and Thou'. It is beyond this I and you where love becomes an institution that transforms love from being a means to life into the most meaningful end. Here love starts to govern the romantically involved individuals.

5.7 Simmel has captured this additional dimension of love and explicitly pointed at the institutional autopoetic dimension of love:

\begin{abstract}
'As soon as love exists in this species determined and teleological sense, it is also something different that transcends this status. Of course it still remains an aspect of life, but in a special way: The real dynamic of life, the process of life as naturally propelled, now exists for its sake. It signifies a meaning and a definitive state that is completely disengaged from the teleology of life. Indeed, insofar as the connection with this teleology persists, it is actually reversed: The lover feels that life now has to serve love.' (Simmel 1984: 166)
\end{abstract}

Simmel's descriptions reflect perfectly what we found in the narrations of those informants who were in a love relationship - love is more than just an emotion and a link between individuals. As soon as love is felt and shared it turns into an end that creates and establishes certain romantic (intimate) norms and rules, parallelized by an idealized story created by those being in love with each other.

5.9 This is what differentiates romantic love from a linking emotion. Rather than an emotion that mediates the social meaning of some other social phenomenon, rather than an emotion making people feel the norms and rules of some social institution, like this is the case for shame, romantic love fundamentally provides this meaning itself. Romantic love is mean and end, linking emotion, institution and legitimizing story for both being linked by it. Therefore romantic love establishes and re-establishes itself as an institution continuously. This makes it different from other linking emotions because unlike them, romantic love is mediated by other linking emotions like trust and shame.

5.10 It is here where romantic love exceeds the range of the traditional concept 'linking emotion' that we know from authors such as Scheff. That is why we believe that defining love or romantic love as linking emotion is useful but not sufficient. Other definitions of romantic love might help to provide further inside into the social phenomenon romantic love. Luhmann, Beck and Beck-Gernsheim and especially Simmel point at possible theoretical directions.

\title{
Conclusion
}

6.1 If we look at our rich empirical data, we see that people use love as both individual feeling/emotion and social bond. In this sense defining love as linking emotion is not wrong. Nevertheless, according to our analysis romantic love is a very special linking emotion, different from other linking emotions such as grief, shame or belonging.

6.2 As we have shown within this article, romantic love has (at least) 4 different sides. Romantic love is feeling, bond, two-sided ideal and institution. Romantic love unites subjective with objective culture. It is reciprocal, social and individual, at the same time. It is means and end to lover's actions and interactions. Furthermore, it has certain aspects of a religious phenomenon, and it is somehow autopoetic. It is here where the range of the concept 'linking emotion' seems too small. If we define romantic love as a linking emotion we would overlook that romantic love not only links individuals with each other but also marks the rules and norms for such a linking process.

6.3 However, on an analytical level the concept linking emotion might be helpful to shed further light on the research of love and might be one step towards a more open debate on the meaning of love. In fact, in our empirical material, the dimensions of love that most informants used and combined explicitly when they talked about experiences of and with romantic love were romantic love as a feeling, as an emotion, as performance and as a link. These aspects of romantic love that we encountered in people's explicit and implicit narrations of love can be perfectly captured with the concept linking emotion. 


\section{Notes}

Compare with Felmlee and Sprecher (2006)

The project Forms of Commitment in Love relationships and the Expression(s) of Emotions in Times of Electronic Communication research was financed by the Spanish Ministry of Science and Innovation

\section{References}

BECK, U and Beck?Gernsheim E, (1995) The Normal Chaos of Love, Cambridge: Polity Press.

BEN-ZE'EV, A, (2001) The Subtlety of Emotions, Massachusetts: MIT Press Berger, Berger P and Luckmann, T, (1991) The Social Construction of Reality, London: Penguin Books.

CAMPBELL, C, (1987) The Romantic Ethic and the Spirit of Modern Consumerism, Oxford, UK; New York, NY, USA: Basil Blackwell.

CANTÓ MILÀ, N (2013) Simmel in the Archive - the Conflict of Late Modern Culture in Fujiyoshi, K.Archives for Maintaining Community and Society in the Digital Age. Koyasan, Japan: Koyasan University Press.

COLLINS, R, (2004) Interaction Ritual Chains, Princeton and Oxford: Princeton University Press. [doi:10.1515/9781400851744]

FELMLEE, D H and Sprecher, S, (2006) Love in The Handbook of the Sociology of Emotions, New York: Springer.

GLASER, B, (1992) Basics of Grounded Theory Analysis, Mill Valley: Sociology Press.

GRECO, M and Stenner, P, (2008)Emotions: a social science reader, London: Routledge.

HOCHSCHILD, A R, (1983) The managed heart?: commercialization of human feeling, Berkeley: University of California Press.

ILLOUZ, E, (2012) Why Love Hurts- A Sociological Explanation, Cambridge: Polity Press.

ILLOUZ, E, (2009) 'Emotions, Imagination and Consumption - A new research agenda'. Journal of Consumer Culture 9(3): p. 377-413. Retrieved November 29, 2012. [doi:10.1177/1469540509342053]

ILLOUZ, E, (2007) Cold Intimacies: The Making of Emotional Capitalism, Cambridge: John Wiley \& Sons.

ILLOUZ, E, (1997) Consuming the Romantic Utopia: Romantic love and the Cultural Contradictions of Capitalism, Berkeley: University of California Press.

KEMPER, T , (1987) 'How Many Emotions Are There? Wedding the Social and the Autonomic Components', The American Journal of Sociology 93(2):p. 263-289. [doi:10.1086/228745]

KEMPER, T D, (1989). Romantic love and Like and Romantic love and Love in Franks D D and McCarthy E D The Sociology of Emotions: Original Essays and Research Papers, p. 249-268 Greenwhich, CT: JAI Press.

LUHMANN, N, (1986) Love As Passion: The Codification of Intimacy, Harvard: Harvard University Press.

MAUSS, M, (2002) The Gift: Forms and Functions of Exchange in Archaic Societies London: Routledge. 
SCHEFF, T, (2010) What's Romantic love Got to Do with It?: The Emotional World of Popular SongsBoulder: Paradigm Publishers.

SCHEFF, T, (2000) Shame and the Social Bond: A Sociological Theory, Sociological Theory, Vol. 18, Issue 1, p. 84-99. [doi:10.1111/0735-2751.00089]

SEEBACH, S, (2015) Romantic Love and Society: Special Social Forms and the Master Emotion, London: Routledge.

SEEBACH, S, (2013). Is Being Connected Enough - Electronic Communication in Contemporary Romantic love Relationships in Les Cahier Numerique, 9/2, 2013, p.77-103

SIMMEL, G, (1997) Simmel on culture??: selected writings, London, edited by Frisby, D, and Featherstone, M, Thousand Oaks, California: Sage Publications.

SIMMEL, G, (1984) Georg Simmel, on Women, Sexuality, and Loveedited by Oakes G, New Haven: Yale University Press.

SIMMEL, G, (1950). The Sociology of Georg Simmel, edited by Kurt Wolff, New York: Simon \& Schuster.

STERnBERG, R J, (1999) Romantic love Is a Story: A New Theory of Relationships Oxford: Oxford University Press.

STRAUSS, A and Corbin, J, (1997) Grounded Theory in Practice, London et alt.: Sage 